\title{
Effects of Austenitising Conditions on the Microstructures and Mechanical Properties of Martensitic Steel with Dual Matrix Structure
}

\author{
K.A. Bello ${ }^{*}$, S.B. Hassan and O. Aponbiede \\ Department of Metallurgical and Materials Engineering, Ahmadu Bello University, Zaria, \\ Nigeria \\ *Corresponding Author: kabello@abu.edu.ng, bellkam@yahoo.com.
}

\section{ABSTRACT}

A new high strength steel with dual matrix structure and exceptionally high toughness plus ductility have been produced by intermediate quenching of $0.22 \_w t \%$ C microalloyed steel. The treatment consisted of initial austenitization and rapid quenching of the steel samples to achieve a fully martensitic state followed by annealing in the intercritical $(\alpha+\gamma)$ region of $730^{\circ} \mathrm{C}-810^{\circ} \mathrm{C}$ for the period of 30, 60 and 90_minutes. These samples were subsequently quenched to obtain dual phase microstructure containing varying proportions of ferrite and martensite constituents. The mechanical properties of the samples were measured according to ASTM standard and their microstructures were analyzed by optical microscopy. The experimental results show that martensitic dual phase (MDP) steel samples developed within the intercritical temperature range of $770-790^{\circ} \mathrm{C}$ revealed finer martensite and precipitatefree ferrite microstructure. The tensile and impact properties of the developed HMDP steels increased with intercritical annealing (ICA) temperatures, with an optimum properties obtained at $790^{\circ} \mathrm{C}$ mainly due to finer microstructure of the constituent phases and absence of carbide precipitate that permit ease of dislocation flow. A further increase in the intercritical annealing temperature beyond $790^{\circ} \mathrm{C}$ led to general decrease in the mechanical properties. This is attributed to the formation of coarse structure in this region. The results further show that with increasing intercritical treatment time from 30 to 90 minutes, the general mechanical properties of the MDP steels were found to increase except at the higher 
temperature of $810^{\circ} \mathrm{C}$ which showed decreasing values. In general, the tensile strengths and ductility as well as the impact properties of the developed dual phase steel samples are greatly improved with the intercritical heat treatment investigated.

Keywords: Intercritical temperature; dual phase steels; microstructure; microalloyed steel; dual matrix

\section{INTRODUCTION}

The interest for high strength Dual-phase (DP) steel sheets having excellent ductility has increased significantly in recent years in various industries and in the automotive industry in particular [1]. Obviously, the potential that has encouraged the development and adoption of these steels in the industry are mainly motivated by their possibilities to improve productivity and reduce auto body weight, and to increase the passenger safety at a competitive price often equal or lower than that of conventional material solutions of similar strength level $[1,2]$.

Dual-phase steels are characterized by a microstructure consisting of martensite in a polygonal ferrite matrix. The hard martensite particles provide substantial strengthening while the ductile ferrite matrix gives good formability [2]. The martensite/ferrite dual phase mixture acts like a particle-reinforced composite. The tensile strength of the composite can be approximated by simple rule-of-mixture [3,4]: $\delta_{\mathrm{DP}}=\mathrm{V}_{\mathrm{F}} \delta_{\mathrm{F}}+\mathrm{V}_{\mathrm{M}} \delta_{\mathrm{M}}$, where $\delta$ is tensile strength and $\mathrm{V}$ is the volume fraction of the phase and the subscripts DP, F and M indicate the composite dual phase structure and the ferrite and martensite phases respectively. Both the phase fractions and the properties of martensite can be adjusted by controlling the steel chemistry and intercritical annealing (ICA) temperature in the ferrite plus austenite region just prior to rapid quenching [4].

Review of the relevant literature shows that the strength of DP steel appear to increase by increasing the amount of martensite, as the martensite is the harder phase [3-5]. This, however, might be done at the expense of ductility and toughness and for this reason such are inappropriate for undergoing various deformation processes $[5,6]$. Recently, the degradation of ductility and impact toughness of DP steels has been receiving attention and this 
phenomenon has been attributed to the formation of coarse martensite phases as the intercritical annealing temperature increases $[3,5,6]$. It has been shown that the ductility and fracture toughness can satisfactorily be optimized by developing microstructures with fine distribution of ferrite and martensite in DP steel either by introducing new alloy design or adopting an appropriate heat treatment procedure $[3,6,7]$. On the basis of alloying design, the new chemistries are low in carbon and rich in hardenability enhancing element such as Mn and Si in optimum ratio $[4,7,8]$.

The present study aims at developing high martensite dual-phase steels by an intermediate quench (IQ) heat treatment technique. To these purposes, this paper present the effects of the intercritical thermal treatment parameters (temperature and time) on the microstructures and mechanical properties of $0.22 \mathrm{wt} \% \mathrm{C}$ microalloyed steel.

\section{EXPERIMENTAL DETAILS}

\subsection{Material and Heat Treatment.}

Commercial microalloyed steel provided for this study was obtained in the form of $15 \mathrm{~mm}$ thick plate (hot-rolled condition). The actual composition as determined by chemical analysis is given in table1. The tensile and izod impact samples were cut from the plate and machined to a standard section and then normalized at $950^{\circ} \mathrm{C}$ for $1 \mathrm{~h}$ to remove the effect of prior heat treatment.

Table 1: Chemical Compositions of the Steel Used.

\begin{tabular}{|l|l|l|l|l|l|l|l|l|}
\hline$\% \mathrm{C}$ & $\% \mathrm{Mn}$ & $\% \mathrm{Si}$ & $\% \mathrm{P}$ & $\% \mathrm{~S}$ & $\% \mathrm{Mo}$ & $\% \mathrm{~V}$ & $\% \mathrm{Ti}$ & $\% \mathrm{Al}$ \\
\hline 0.22 & 1.20 & 0.25 & 0.025 & 0.025 & 0.001 & 0.004 & 0.002 & 0.051 \\
\hline
\end{tabular}

All the machined samples were subjected to intermediate quench heat treatment which involves double quench operation. These samples were initially austenitized at $920^{\circ} \mathrm{C}$ in a carbolite muffle furnace, soaked for 60minutes and then quenched in $9 \%$ iced brine solution to obtain a fully martensitic structure which was used as the starting microstructure in this investigation. The individual specimen was subsequently intercritically annealed at temperatures between $730{ }^{\circ} \mathrm{C}$ and $810{ }^{\circ} \mathrm{C}$ and held for the period of 30, 60, and 90_minutes 
respectively for each of the temperature regimes. These were finally quenched in oil to get different proportion of dual phase structure of ferrite and martensite. Throughout these heat treatments, the temperature of each specimen was monitored by a thermocouple.

\subsection{Material Characterization and Testing}

Microstructures of the heat-treated samples were examined by optical microscopy using a standard metallographic preparation procedure (samples were etched with $2 \%$ Nital solution after grinding and polishing). A wild M50 metallurgical microscope was used for the metallographic characterization.

Following the microstructural studies, tensile and izod impact testing of all the heat-treated samples were conducted per ASTM standard. Tensile testing was performed on round specimens with $50 \mathrm{~mm}$ gauge length and diameter of $12.5 \mathrm{~mm}$ using Monsanto type WTensiometer. Izod V-notch impact tests were conducted in accordance with ASTM standards (BS.131) using a pendulum-type impact-testing machine with 186.1joules capacity and at a velocity of $3.5 \mathrm{~m} / \mathrm{s}$. All tests were carried out under laboratory air environment $\left(32^{\circ}\right)$ and minimum of three samples were tested for each of heat treatment conditions investigated.

\section{RESULTS AND DISCUSSION}

\subsection{Microstructure}

Upon quenching of the steel from the intercritical temperature in oil held at different times, austenite transforms to martensite producing ferrite-martensite dual phase structure. Figures 1-5 show the optical microstructure of samples processed by intermediate quench (IQ) heat treatment technique. The structures of martensitic dual phase (MDP) steel obtained show uniform distribution of lath martensite in ferrite matrix. The distribution is similar to those reported for conventional DP steels [10].

At lower intercritical annealing (ICA) temperatures, the microstructures of the MDP steel specimens obtained reveal fine particles of undissolved carbide precipitates (black dots) as seen in Figures (1) and (2). It is widely reported $[6,11]$ that these precipitates are formed during the reheating process to the ICA temperature. The amount of carbide precipitates 
decrease as the intercritical temperature increases and such carbides are not present in specimens intercritically annealed at $770^{\circ} \mathrm{C}, 790^{\circ} \mathrm{C}$ and $810^{\circ} \mathrm{C}$, as in Figures (3) to (5).

For all the samples, the micrographs show martensite layers thickening on the ferrite grain boundary until it forms a continuous network around the ferrite grains as the time increases from 30 to 90 minutes for each of the increasing temperature. According to Barros et al. [9], this is a result of the increase in the martensite content with intercritical treatment times.

Observation of the specimens prepared at lower ICA temperature also show coarsening of ferrite structure while coarse martensite was found at higher ICA temperature. At ICA temperature from 770 to $790{ }^{\circ} \mathrm{C}$, the microstructure developed comprised mostly of finer ferrite and martensite, as shown in fig. (3) and (4).

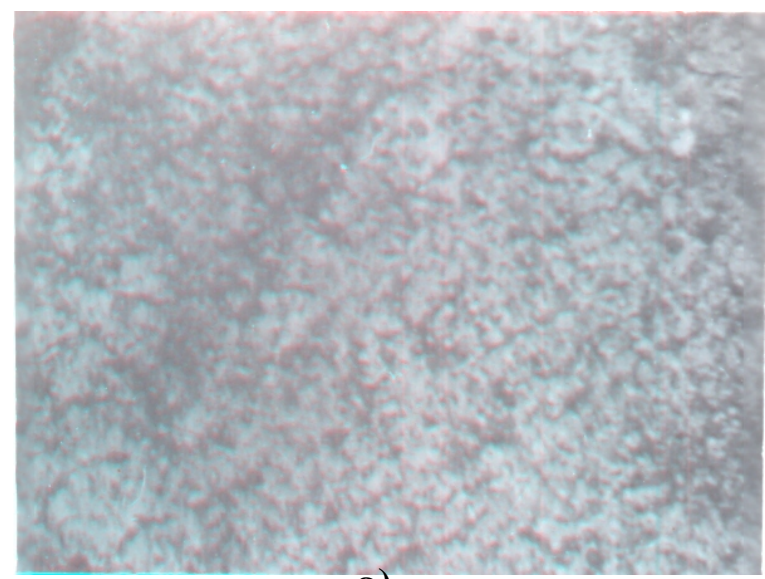

a)

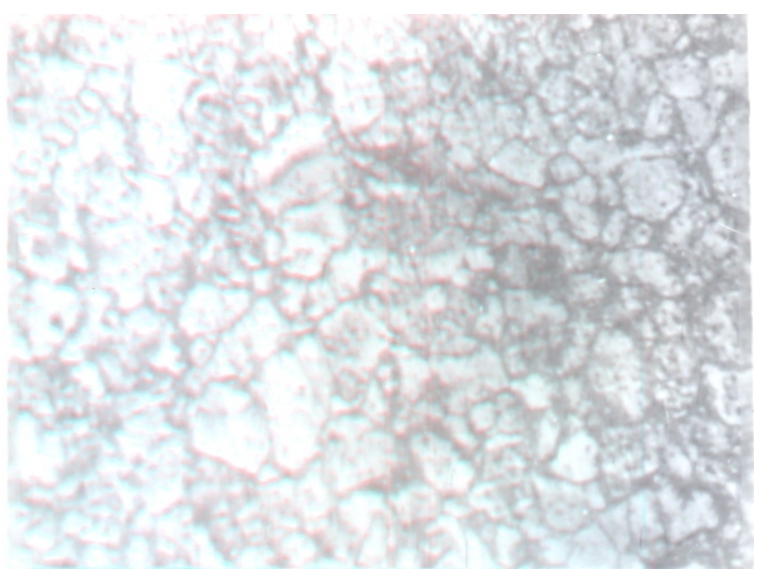

b)

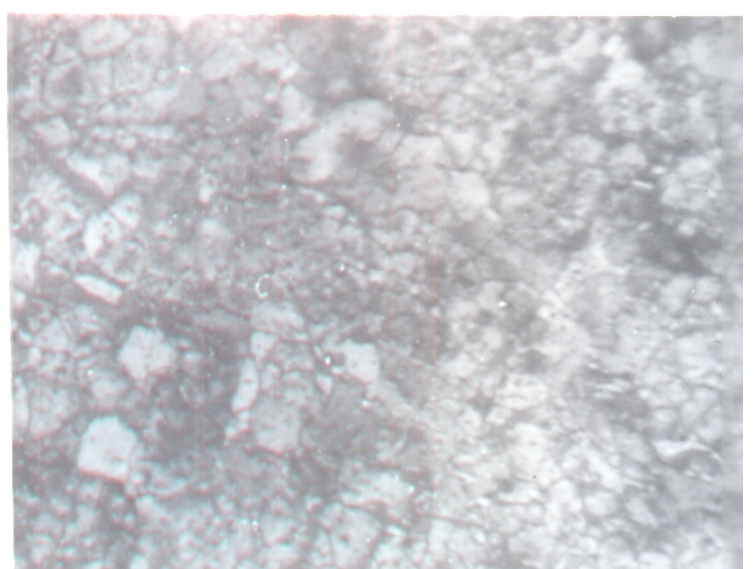

c)

Figure 1: Photomicrograph of MDP steels intercritically annealed at $730^{\circ} \mathrm{C}$ for (a) $30 \mathrm{~min}$ (b) 60min (c) 90min. The structure showing distribution of martensite (dark), undissolved carbide (black dot) and ferrite (light). .2\%Nital etch. 


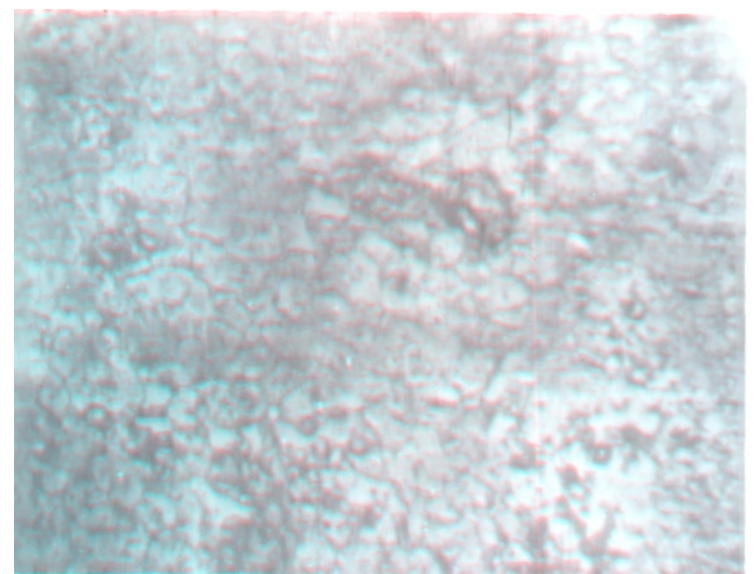

a)

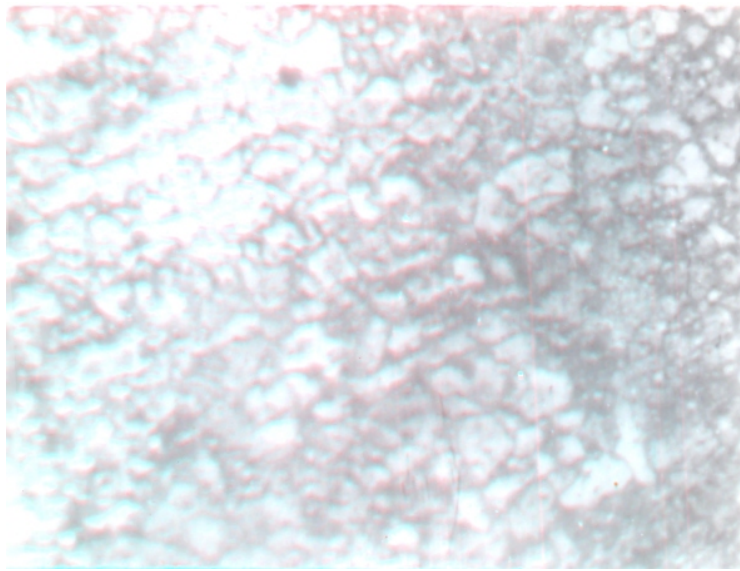

b)

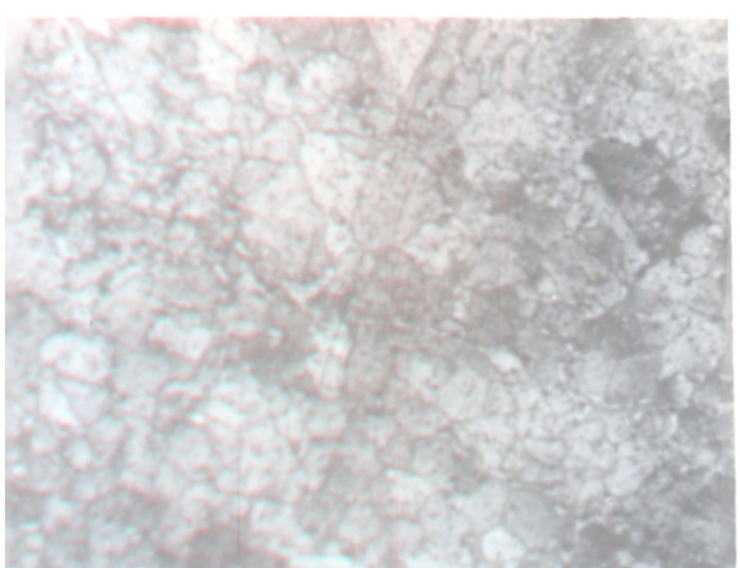

c)

Figure 2: Photomicrograph of MDP steels intercritically annealed at $750^{\circ} \mathrm{C}$ for (a) $30 \mathrm{~min}$ (b) $60 \mathrm{~min}$ (c) $90 \mathrm{~min}$.The structure showing distribution of martensite (dark), undissolved carbide (black dot) and ferrite (light). .2\%Nital etch. 


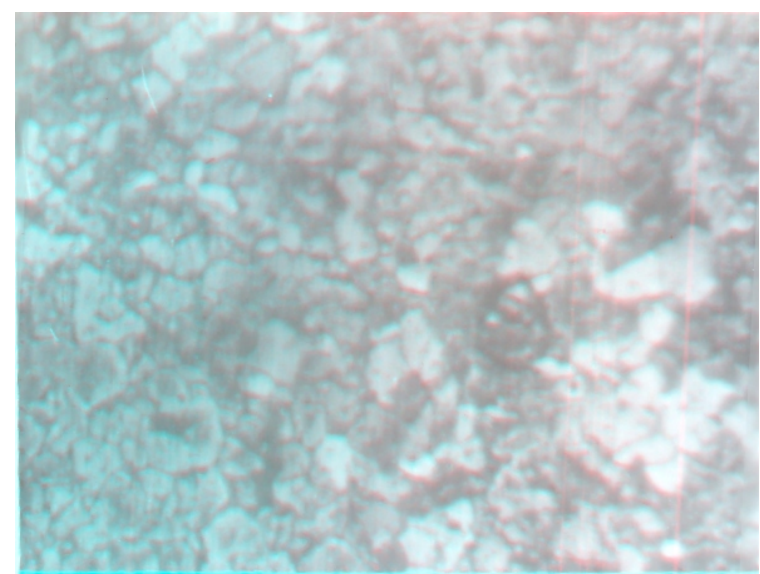

a)

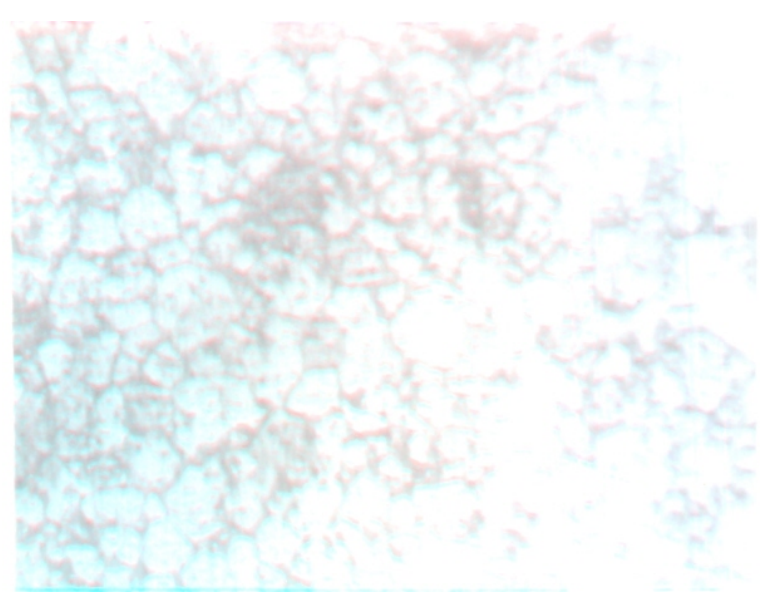

b)

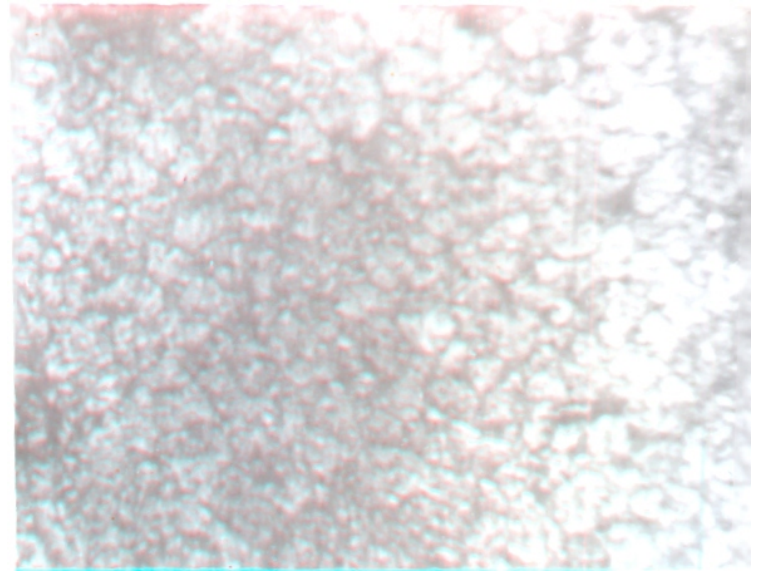

c)

Figure 3: Photomicrograph of MDP steels intercritically annealed at $770^{\circ} \mathrm{C}$ for (a) $30 \mathrm{~min}$ (b) 60min (c) 90min. The structure showing distribution of martensite (dark) and ferrite (light). .2\%Nital etch. 


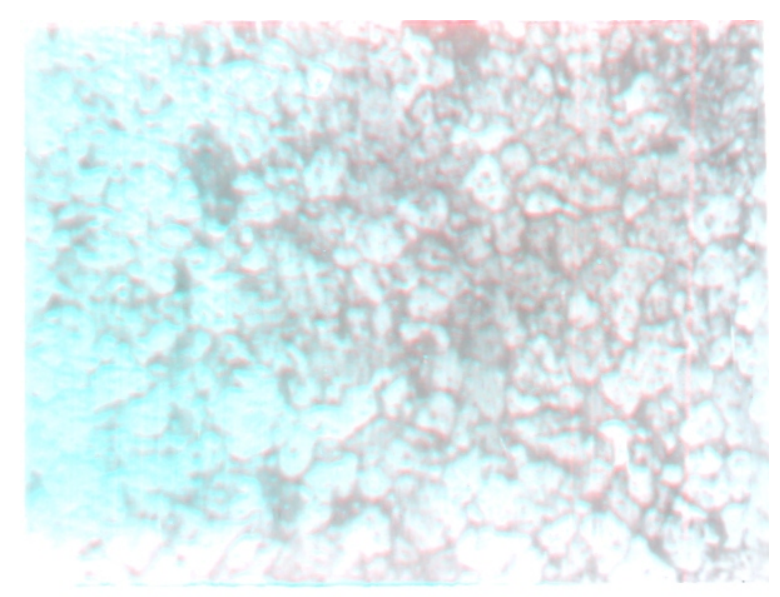

a)

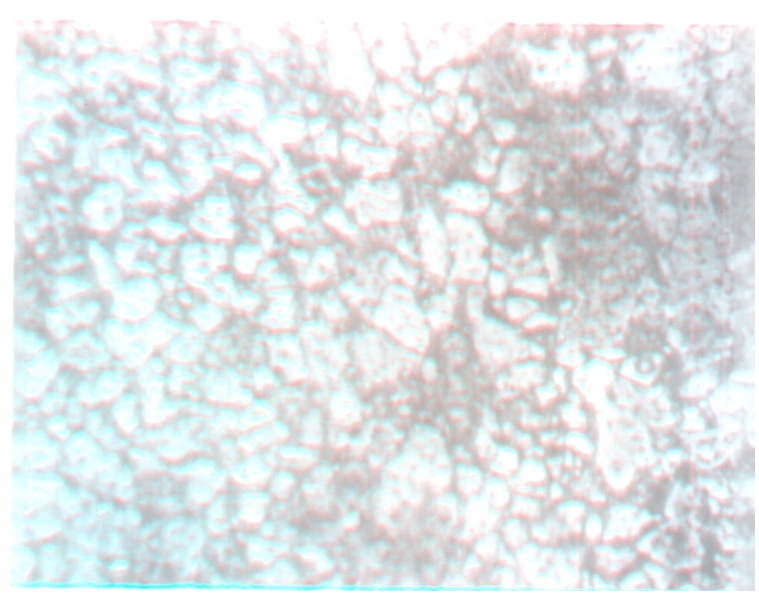

b)

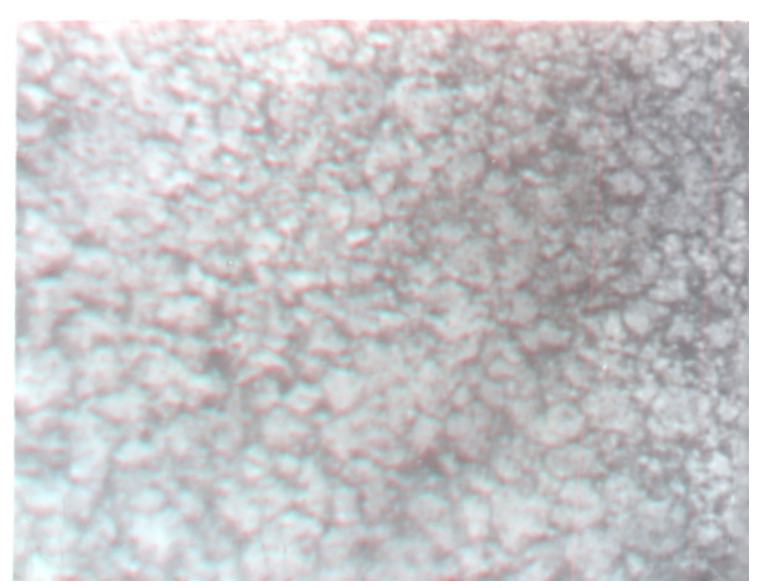

c)

Figure 4: Photomicrograph of MDP steels intercritically annealed at $790^{\circ} \mathrm{C}$ for (a) $30 \mathrm{~min}$ (b) $60 \mathrm{~min}$ (c) $90 \mathrm{~min}$. The structure showing distribution of martensite (dark) and ferrite (light). .2\%Nital etch. 


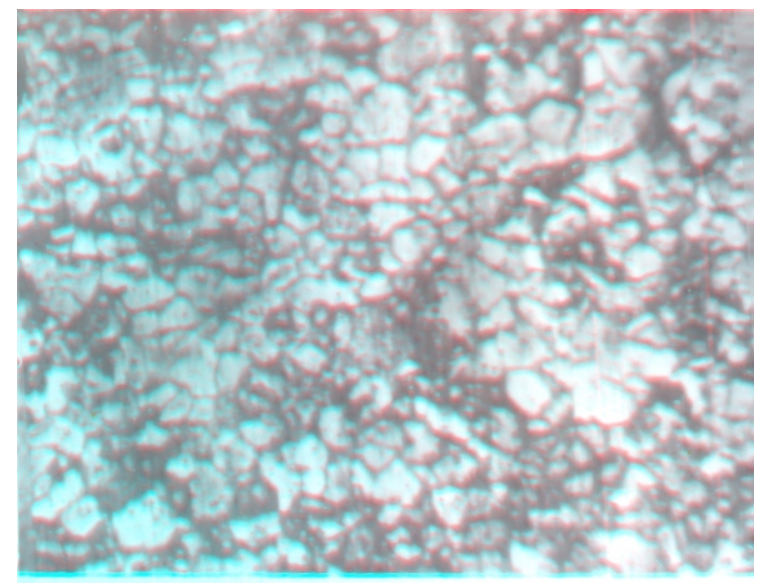

a)

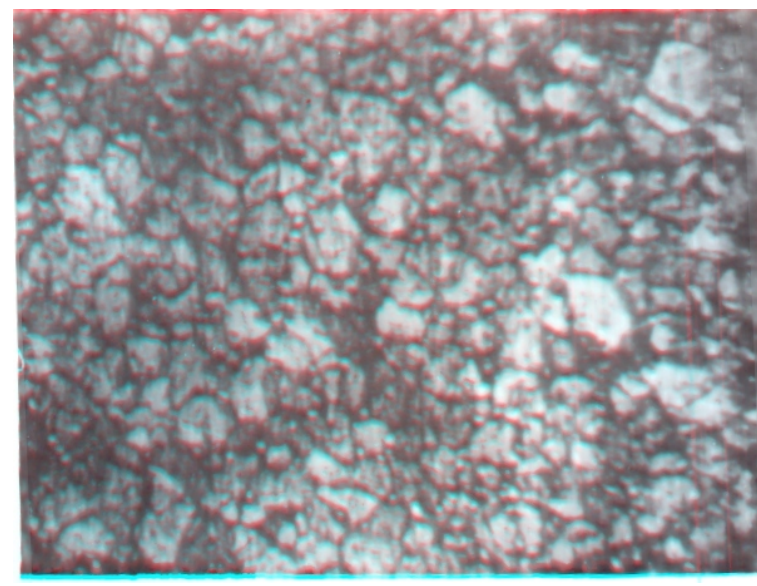

b)

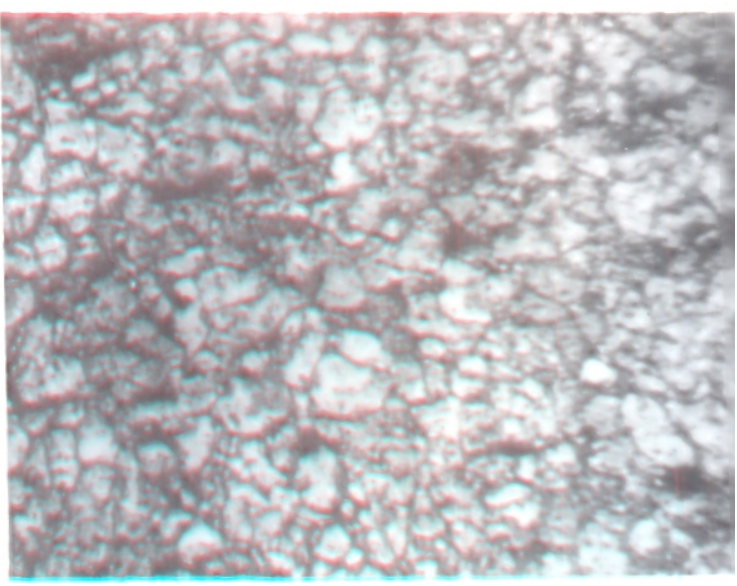

c)

Figure 5: Photomicrograph of MDP steels intercritically annealed at $810^{\circ} \mathrm{C}$ for (a) $30 \mathrm{~min}$ (b) $60 \mathrm{~min}$ (c) $90 \mathrm{~min}$ The structure showing coarse distribution of martensite (dark) and ferrite (light). .2\%Nital etch.

\subsection{Tensile Properties}

Figures 6-8 report tensile test results of IQ-treated MDP steel sample. It is apparent from the results that the tensile properties data readily change with intercritical annealing treatment temperatures. It was found that MDP steels show continuous yield behaviour and its proof strength at $0.2 \%$ strain is taken as the yield strength. The absence of discontinuous yielding in conventional ferrite-martensite steels has been explained in term of the high dislocation density surrounding the martensite islands [12]. Beynon et al. [8] has further pointed out that during the austenite to martensite transformation, a hard deformation resistance phase is introduced into microstructure and due to the volume expansion that takes place during the transformation of austenite to martensite, mobile dislocation are introduced into the 
surrounding ferritic constituent matrix. The mobility of these dislocations is responsible for the continuous yielding behaviour attributed to dual phase steel grades.

As seen from the figures, the tensile strength and yield strength (Fig. 6 and 7 respectively) initially increase gradually with ICA temperatures, reaching maximum values at a temperature around $790{ }^{\circ} \mathrm{C}$ and then decreases with a further increase in ICA temperature up to $810{ }^{\circ} \mathrm{C}$. From figure 8 , it is evident that IQ-treatment does appear to significantly improve the ductility of MDP steel as it display similar trend with the strength. However, this result is unusual and opposed to the conventional fact that ductility generally decreases as the strength increased.

According to Sudhakar et al. [13], it was reported that the increase in strength obtained in DP steels is mainly attributed to (a) the load bearing capability of martensite in the DP structures, and (b) the fact that deformation in the ferrite phase is constrained by martensite. It has been further reported [11] that the yield strength and ultimate tensile strength of DP steels are linearly related to the amount of martensite, which increases with ICA temperatures. Recently, it has been observed that dual phase steel with finer microstructure exhibits higher ductility [6]. On comparison, the result of the ductility obtained in this investigation appears to agree with previous finding.

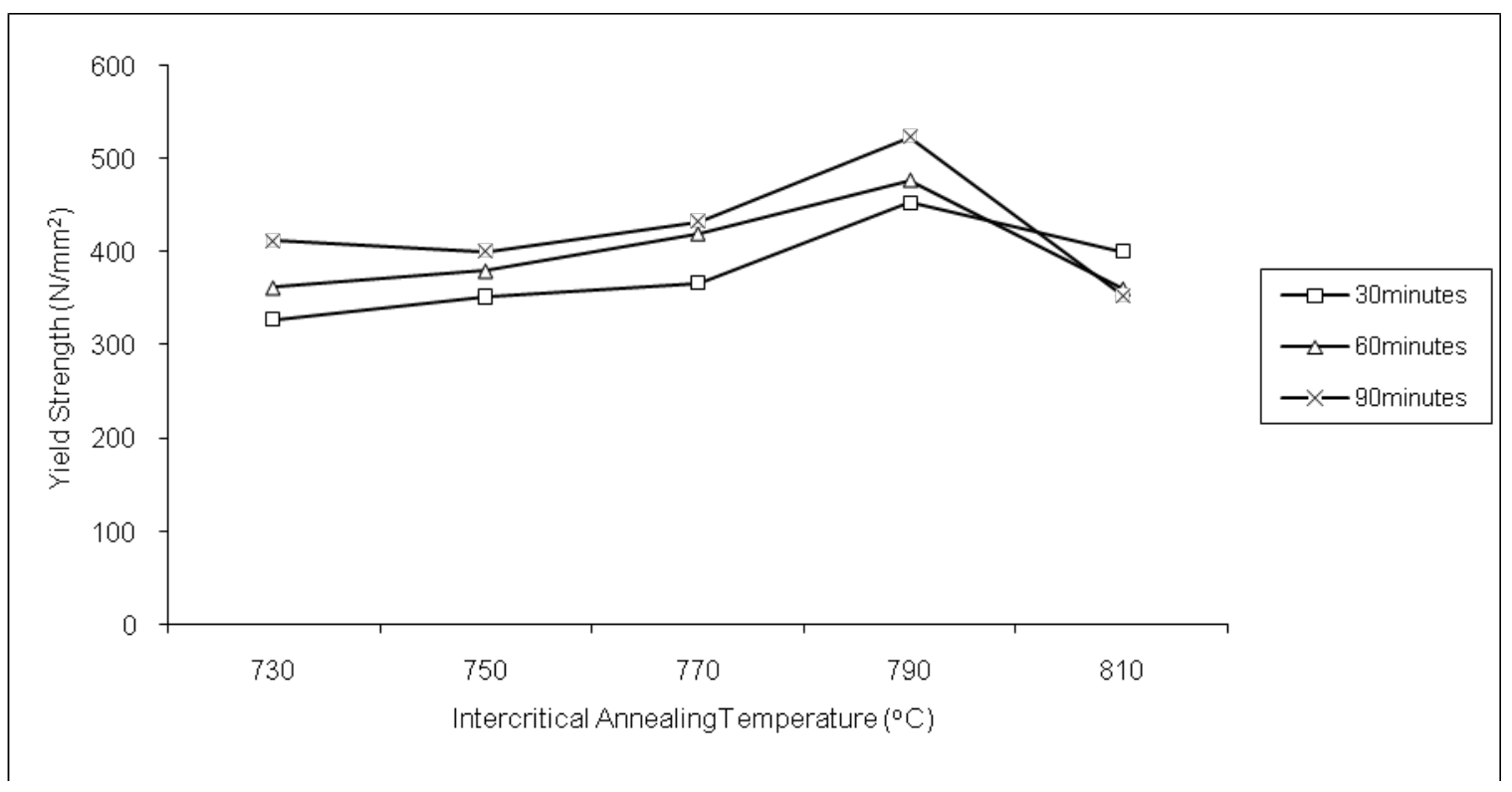

Figure 6: Yield strength of intercritically annealed MDP steel at various intercritical temperatures and times. 


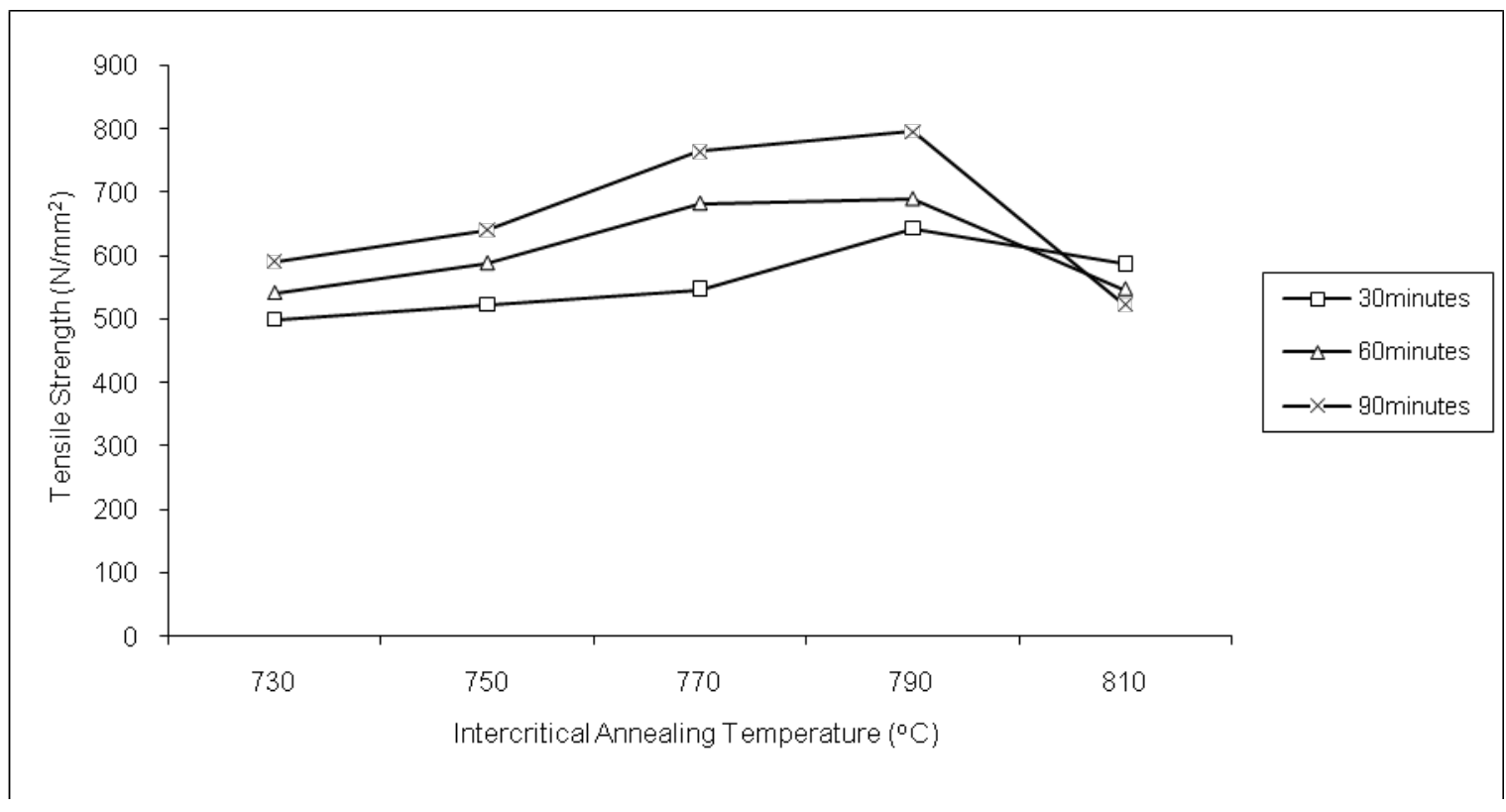

Figure 7: Tensile strength of intercritically annealed MDP steel at various intercritical temperatures and times.

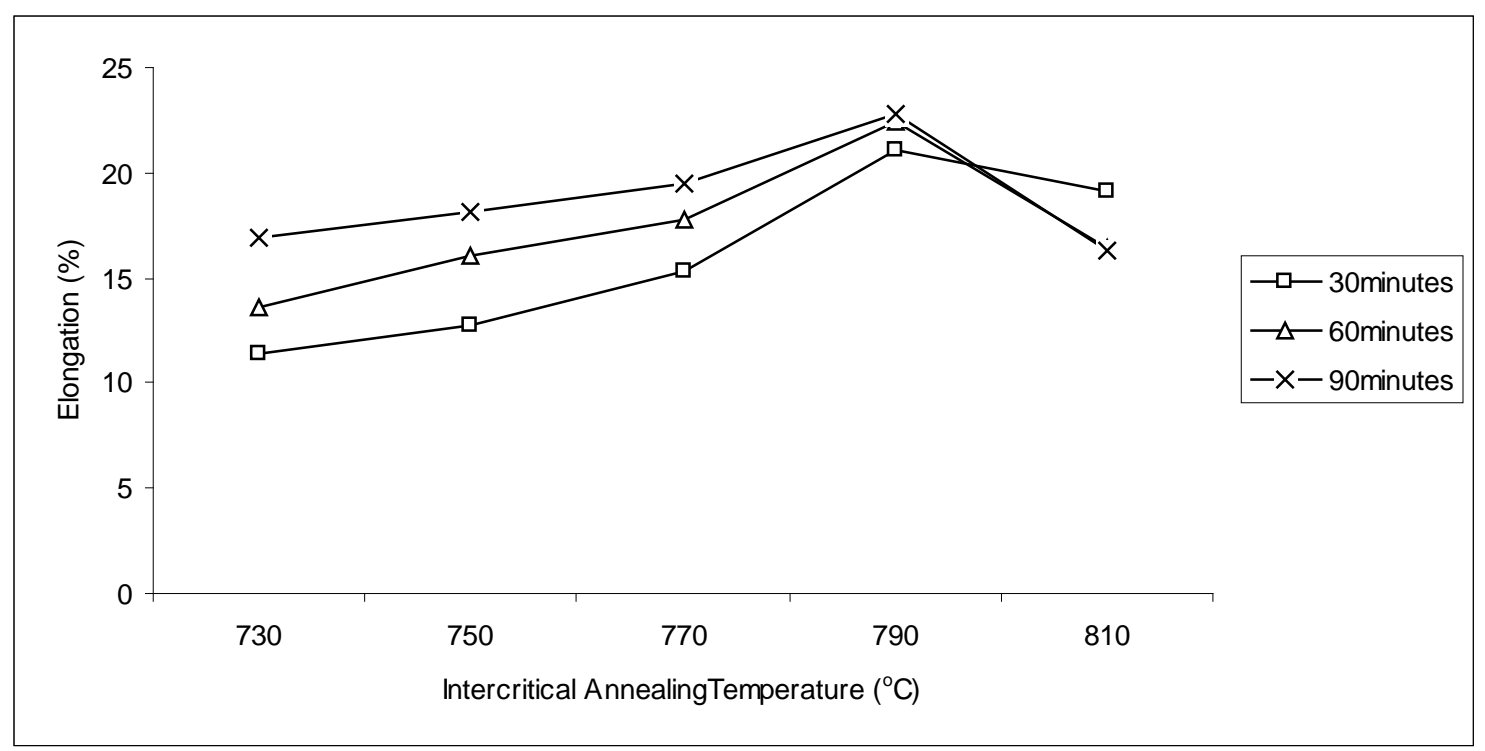

Figure 8: Percentage elongation of intercritically annealed MDP steel at various intercritical temperatures and times.

This result also shows that tensile properties of MDP steel increases over the range of $730{ }^{\circ} \mathrm{C}$ $790{ }^{\circ} \mathrm{C}$ as the intercritical holding time is increased from 30 to 90_min.

\subsection{Impact Toughness}

Figure 9 illustrate plot of fracture impact energy versus intercritical annealing temperature (see Figure 9). It can be seen that impact energy value of the MDP steel increases as ICA 
temperature increases and then decreases. This trend is similar to the one obtained for the tensile properties. This situation is associated with the morphology of the microstructural constituents in MDP steel samples. The lower tensile strength, ductility and toughness obtained at lower intercritical temperature could be attributed to the relatively coarser ferrite with carbide precipitates whereas for lower strength at higher intercritical temperature is due to coarser martensite. Thus the optimum value obtained for all the mechanical properties investigated occurred at intercritical temperature of $790^{\circ} \mathrm{C}$, which corresponds to the microstructure comprised mostly of finer ferrite and martensite. It, therefore, appears that strength, ductility and toughness are associated with finer martensite and finer precipitatefree ferrite that permit ease of dislocation flow owing to the absence of barriers such as the undissolved carbides.

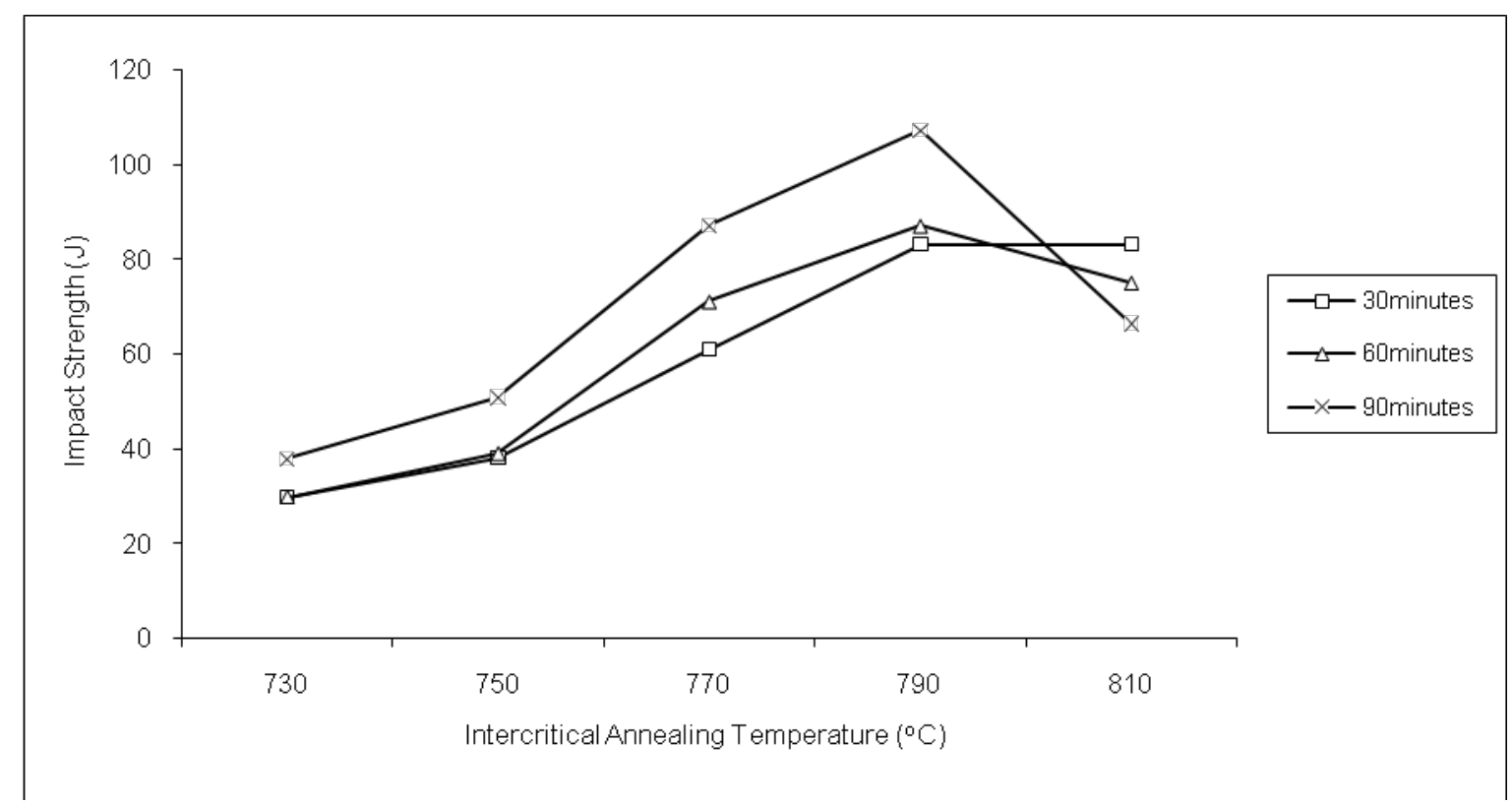

Figure 9: Impact strength of intercritically annealed MDP steel at various intercritical temperatures and times.

The impact toughness of MDP steel samples increase with the intercritical time from 30 to 90minutes for each of the intercritical temperatures except at higher intercritical temperature where further increase to about $810^{\circ} \mathrm{C}$ gave decrease in the properties of the steel as time increases. This is probably due to the continued coarsening of martensite phase in this intercritical region [9]. 


\section{CONCLUSIONS}

From the results of this research work, the following conclusions can be drawn.

1) The as-received microalloyed steel samples respond well to heat treatment, both during quenching and intercritical annealing treatments.

2) Intermediate quenching treatment results in substantial improvements in the general mechanical properties of developed MDP steels.

3) Continuous yielding was found to occur for MDP steel samples intercritically annealed in the range $730^{\circ} \mathrm{C}-810^{\circ} \mathrm{C}$ due to the introduction of mobile dislocations into the surrounding ferritic constituent matrix during rapid transformation of austenite to martensite.

4) Finer distribution of ferrite and martensite phases were obtained for IQ-treated MDP steel samples treated within the intercritical annealing treatments temperature range of 770$790^{\circ} \mathrm{C}$. However, samples that were intercritically annealed at $810^{\circ} \mathrm{C}$ exhibited coarse structure and the MDP steels heat-treated at lower intercritical annealing temperatures $\left(730^{\circ} \mathrm{C}-750^{\circ} \mathrm{C}\right)$ were found to contain coarse ferrite with carbide precipitates; the effect of which lowered the properties of the material.

5) Increasing the intercritical treatment for the period up to 90_mins within the temperature range of $730^{\circ} \mathrm{C}-750^{\circ} \mathrm{C}$ causes a rise in the tensile and impact strength

6) Increasing the intercritical annealing treatment temperature beyond $790^{\circ} \mathrm{C}$ reduces the tensile and fracture toughness properties of the developed MDP steel.

7) The yield strength, tensile strength, \% elongation and impact toughness of the developed martensitic dual phase steel increased to a maximum value of $524 \mathrm{~N} / \mathrm{mm}^{2}, 795 \mathrm{~N} / \mathrm{mm}^{2}$, $22.8 \mathrm{~N} / \mathrm{mm}^{2}$, and 107joules respectively when intercritically annealed at temperature of $790^{\circ} \mathrm{C}$. This is attributed to the finer distribution of ferrite and martensite constituents as well as presence of precipitate-free ferrite in this region causing an ease of dislocation flow in the material due to the absence of barriers such as undissolved carbides precipitates. The 
investigation therefore shows that intercritical treatment accompanied with grain refinement is strikingly successful in improving the mechanical properties of the developed MDP steels.

8) The general mechanical properties of the developed MDP steel were substantially raised with intercritical annealing time from 30 to 90_minutes.

\section{ACKNOWLEDGEMENTS}

This work was carried out at Ahmadu Bello University and Obafemi Awolowo University Metallurgical laboratories as part of KAB's MSc thesis. The authors are grateful to the management of Islamic Education Trust Minna, Nigeria for funding assistance. KAB's appreciate the special assistance rendered by Dr. L.E. Umoru and Dr. A. Oyetunji.

\section{REFERENCES}

[1] S.J. Kim, C.G. Lee, I.C. Choi, Sunghak Lee, Effects of Heat Treatment and Alloying Elements on the Microstructures and Mechanical Properties of 0.15 Wt Pct C transformation-Induced Plasticity-Aided cold-Rolled Steel Sheets, Metall. Mater.Trans. A, Vol. 32A, (2001) 505.

[2] P. Giorgio, C.C. Maria, Metallurgically Based Development of Dual Phase Thin Hot Strip, Acciaieria Arvedi S.P.A., Ceremona Italy, (22004) 1-2.

[3] W. Saikaly, X. Bano, C. Issartel, G. Rigaut, The Effects of Thermomechanical Processing on the Precipitation in an Industrial Dual Phase Steel Microalloyed with Titanium, Metall.Trans. A, Volume 32A, (2001) 1939.

[4] S.B. Pritchard, A.J. Trowsdale, Dual Phase Steel-High Strength Fasteners Without Heat Treatment, Corus Construction and Industrial, U.K., (2002) 1-10.

[5] K. Hulka, Dual Phase and Trip Steels, ASM, Metal park Ohio, (2000) 1-4.

[6] A. Bag, K.K. Ray, E.S Dwarakadasa, Influence of Martensite Content and Morphology on the Toughness and Fatigue Behaviour of High-Martensite Dual-Phase Steels, Metall. Mater.Trans. A, Vol. 32A, (2001) 2207-2213.

[7] T. Waterscoot, L. Kestens, B.C. De Cooman, Hot Rolling Texture Development in CMnCrSi Dual Phase Steels, Metall. Mater.Trans. A, Vol. 33A, (2002) 1091. 
[8] N.D. Beynon, T.B. Jones, G. Fourlaris, Effect of Processing Parameters on the Deformation Behaviour of Low Carbon Dual Phase Strip Steel at High Strain Rates, MS\&T Conference Proceedings, (2004) 459.

[9] A.C. Barros, Microstructure and Mechanical Properties of a Microalloyed Steel after Thermal Treatments, Materials Research Journal, Vol.6, (2003) 118.

[10] V. Raghavan, Physical Metallurgy: Principle and Practice, Prentice-Hall of India Ltd, Delhi, (1989) 97-98, 206-221.

[11] G. R. Speich, Fundamentals of dual phase steels, New York: AIME, (1981) 3

[12] X. Fang, Z. Fan, B. Ralph, P. Evans, R. Underhill, Effects of Tempering Temperature on Tensile and Hole Expansion Properties of a C-Mn Steel, Materials Processing Technology, 132 (2002) 217.

[13] K. V. Sudhakar, E. S. Dwarakadasa, A Study of Fatigue Crack Growth in Dual Phase Martensitic Steel in Air Environment, Bull. Mater. Sci, Vol. 23, (2000) 193-199. 